\title{
Numerical temperature and concentration distributions in an insulated salinity gradient solar pond
}

\author{
Ridha Boudhiaf
}

\begin{abstract}
In this paper, the temperature and concentration distributions in an insulated salinity gradient solar pond are studied numerically in transient regime. The dimensionless governing equations are solved by finite-volume method using SIMPLER algorithm with HYBRID scheme. The pond is filled with a mixture of salt and water to form three zones: upper convective zone (UCZ), non-convective zone (NCZ) and lower convective zone (LCZ). The vertical walls and the bottom of the pond are thermally insulated. The bottom of the pond is black painted. The simulation of the insulated salinity gradient solar pond shows the existence of salt diffusion from the bottom to the free surface. This numerical study shows also that the buoyancy ratio increases and decreases the temperature and concentration in the LCZ and in the UCZ, respectively.
\end{abstract}

Keywords: Salinity gradient solar pond; Solar energy; Concentration; Temperature; Transient regime; Numerical study

\section{Background}

Solar energy constitutes a vast energy source that is abundantly available in all parts of the earth. Solar energy is one of the best alternatives to non-renewable sources of energy. One way to collect and store solar energy in the form of high-density salt water is through the use of salinity gradient solar ponds which can be used to supply thermal energy for different applications, such as process and space heating, production of electricity, water desalination, refrigeration, textile processing, and food industries. A salinity gradient solar pond is a large basin of salty water. In this system, an important quantity of solar radiation is absorbed and converted into thermal energy which is stored in the bottom of this system for a long period (months, seasons, or even a year). A salinity gradient solar pond consists of three zones with different salinities (Figure 1). The top zone (upper convective zone (UCZ)) has a minimum temperature and salt concentration. In this zone, a part of the incident solar radiation is absorbed and the rest is transmitted to the zone

Correspondence: ridhaboudhiaf@yahoo.fr

Laboratory of Electro-Mechanic Systems (LASEM), Mechanical Engineering Department, National School of Engineers of Sfax, University of Sfax (US), Soukra Road, Km 3.5, B.P. 1173, 3038 Sfax, Tunisia below. The bottom zone (lower convective zone (LCZ)) has a maximum temperature and salt concentration. The solar radiation reaching the bottom zone is absorbed and converted into thermal energy which is stored in this zone. These two zones are characterized by almost homogeneous salt concentration due to convective motions. Separating these two zones is the important gradient zone (non-convective zone (NCZ)) where salt concentration and temperature increase with depth. In this zone, water cannot rise because the water above it has less salt content and is therefore lighter. In the same way, water cannot fall because the water below it has a higher salt content and is therefore heavier. The NCZ acts as a transparent insulator due to the lower water conductivity and permits solar energy to be trapped and stored in the bottom zone.

Salinity gradient solar ponds have been widely studied experimentally, analytically, and numerically due to their excellent collection of solar radiation and storage of thermal energy. Many research works have been developed and published (Sodah et al. 1981; Joshi and Kishore 1984; Singh et al. 1994; Sezai and Tasdemiroglu 1995) to control the construction techniques of solar ponds, and different numerical models have been developed to analyze the 


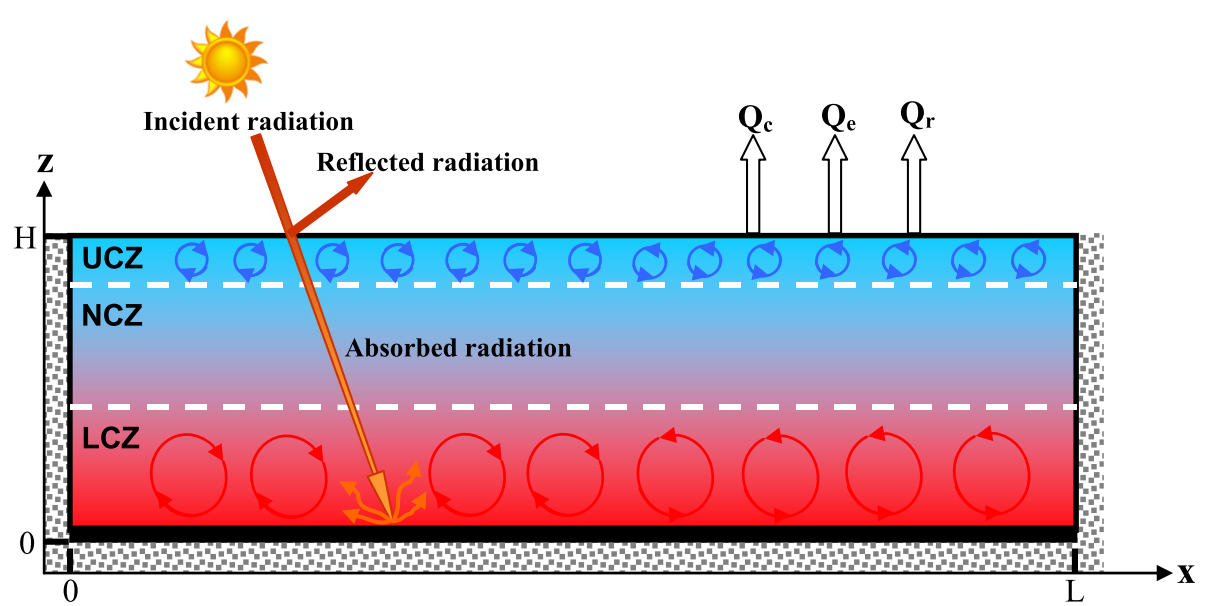

Figure 1 Schematic representation of the insulated salinity gradient solar pond.

performance of salinity gradient solar ponds. Ouni et al. (1998) studied the transient behavior of a onedimensional salinity gradient solar pond in the southern part of Tunisia. In this research work, the temperature is constant in the UCZ and in the LCZ. Kurt et al. (2000) studied experimentally, analytically, and numerically the thermal behavior of a one-dimensional salinity gradient solar pond in transient regime. They showed that the experimental, numerical, and analytical temperatures are constant in the UCZ and in the LCZ. Angeli and Leonardi (2004) studied numerically the salt diffusion in a solar pond using a one-dimensional mathematical model. Ould Dah et al. (2005) studied experimentally the transient evolution of the temperature and concentration profiles in a solar pond with high salinity $\mathrm{NaCl}$ solution. Mansour et al. (2004) studied numerically the transient evolution of the temperature and concentration profiles in a twodimensional salinity gradient solar pond. Kurt et al. (2006) studied experimentally and numerically the performance of a salinity gradient solar pond by using the sodium carbonate salt to create a salinity gradient in the solar pond. They studied the temperature and concentration profiles in the solar pond by developing a one-dimensional mathematical model in transient regime. Hammami et al. (2007) studied numerically the transient evolution of the temperature and concentration profiles in a stratified enclosure with a buoyancy ratio equal to 1,000 . In their research work, the internal heating of the fluid due to the absorption of solar radiation is not considered into account. In the research work of Ould Dah et al. (2010), a one-dimensional numerical model was developed to simulate the transient evolution of the temperature and concentration profiles in a mini solar pond. Karakilcik et al. (2006) studied experimentally and numerically the temperature distributions in an insulated solar pond during daytimes and nighttimes. Sakhrieh and Al-Salaymeh (2013) studied experimentally and numerically the temperature distribution in an insulated solar pond under Jordanian climate conditions. In their research work, the temperature is constant in the UCZ and in the LCZ. El-Sebaii et al. (2011) presented a review study of the history of the solar ponds. They found that the temperature and concentration are almost constant in both the UCZ and the LCZ. Suarez et al. (2010) studied numerically the evolution of the temperature and concentration profiles with time in a salinity gradient solar pond with stable stratified layers.

After reviewing the literature, the anterior numerical and analytical models studied the transient evolution of the temperature and concentration profiles in a onedimensional salinity gradient solar pond. The equations of heat transfer by conduction and mass diffusion are solved by a finite-difference method in transient regime. In these models, the authors neglected the convective movements and assumed that the temperature is constant in the upper and lower convective zones.

In very recent works, the authors have studied the hydrodynamic, heat, and mass transfer behaviors of a twodimensional salinity gradient solar pond in transient regime (Boudhiaf et al. 2012; Boudhiaf and Baccar 2014). The results have shown, in particular, that the internal Rayleigh number, the buoyancy ratio, and the aspect ratio have an important effect, respectively, on the thermal performance of the pond, on the stability, and on the distribution of temperature and velocity fields in the salinity gradient solar pond. In the present paper, we are interested to study numerically the temporal evolution of the temperature and concentration distributions in a twodimensional insulated salinity gradient solar pond under the influence of buoyancy ratio and for an aspect ratio equal to three. The resolution of continuity, momentum, energy, and mass transfer equations is conducted using finite-volume technique discretization in transient regime. 


\section{Mathematical modeling and numerical method Mathematical modeling}

The salinity gradient solar pond is modeled with a two-dimensional rectangular enclosure, as shown in Figure 1, having height $H$ and length $L$ and containing salt and water mixture. It consists of three zones (UCZ, NCZ, and LCZ). The model of Rabl and Nielsen (1975) was adopted to evaluate the amount of solar radiation absorbed at depth $z$. Because of various processes occurring in and out of the salinity gradient solar pond, the study of transient behaviors of the hydrodynamic, heat, and mass transfer in the solar pond is usually complicated. Therefore, some assumptions which do not modify the principles of the system were made for simplifying the analysis as follows:

a. The velocity, temperature, and concentration variation along the $y$-direction is considered small enough so that it is negligible. Therefore, the velocity, temperature, and concentration distributions within the pond are two-dimensional.

b. Both the vertical and the bottom walls of the pond are well insulated and impermeable. The free surface of the pond is subjected to heat losses by convection, evaporation, and radiation.

c. The incident solar radiation upon the free surface of the pond is a supposed constant and has an average value in transient regime.

d. The pond's bottom is black painted in order to raise the absorption of solar radiation by salty water layers. The solar radiation that reaches the bottom of the pond is entirely absorbed by the fluid at this depth.

e. The mixture of salt and water is assumed to be incompressible and Newtonian.

f. The fluid properties are assumed independent of temperature and salt concentration, except the density that varies according to Boussinesq approximation:

$$
\rho(T, C)=\rho_{0}\left(1-\beta_{\mathrm{T}}\left(T-T_{\mathrm{a}}\right)+\beta_{\mathrm{C}}\left(C-C_{\min }\right)\right)
$$

The process of hydrodynamic, heat, and mass transfer in the salinity gradient solar pond can be described by a set of differential equations. To simplify the study, before the numerical calculation, the governing equations are non-dimensionalized with the following dimensionless parameters:

$X=x / H ; Z=z / H ; U=u /(\alpha / H) ; W=w /(\alpha / H) ; \tau=t /\left(H^{2} / \alpha\right) ;$ $P=p /\left(\rho_{0} \alpha^{2} / H^{2}\right)$

$\theta=\left(T-T_{\mathrm{a}}\right) / \Delta T ; \varphi=\left(C-C_{\min }\right) / \Delta C ; \operatorname{Ra}_{\mathrm{T}}=g \beta_{\mathrm{T}} \Delta T H^{3} /(\alpha v) ;$ $\mathrm{Ra}_{\mathrm{I}}=g \beta_{\mathrm{T}} q_{0} H^{4} /\left(\lambda_{\mathrm{w}} \alpha v\right)$

$\operatorname{Ra}_{\mathrm{S}}=g \beta_{\mathrm{C}} \Delta C H^{3} /(\alpha v) ; N=\beta_{\mathrm{C}} \Delta C /\left(\beta_{\mathrm{T}} \Delta T\right) ; \operatorname{Pr}=v / \alpha ; \mathrm{Le}=\alpha / D$ where $H, \alpha / H, H^{2} / \alpha, \rho_{0} \alpha^{2} / H^{2}, \Delta T$, and $\Delta C$ are used as characteristic scales for length, velocity, time, pressure, temperature, and concentration, respectively.

Therefore, the resulting continuity, momentum, energy, and mass transfer equations can be written in dimensionless form as follows:

Continuity equation

$$
\operatorname{div} \vec{V}=0
$$

$U$-Velocity component

$$
\frac{\partial U}{\partial \tau}+\operatorname{div}(U \vec{V}-\operatorname{Pr} \overrightarrow{\operatorname{grad}} U)=-\frac{\partial P}{\partial X}
$$

W-Velocity component

$$
\begin{gathered}
\frac{\partial W}{\partial \tau}+\operatorname{div}(W \vec{V}-\operatorname{Pr} \overrightarrow{\operatorname{grad}} W) \\
=-\frac{\partial P}{\partial Z}+\operatorname{Pr}^{2} a_{\mathrm{T}}(\theta-N \varphi)
\end{gathered}
$$

Energy equation

$$
\begin{aligned}
\frac{\partial \theta}{\partial \tau} & +\operatorname{div}(\theta \vec{V}-\overrightarrow{\operatorname{grad}} \theta) \\
& =0.85 \frac{\mathrm{Ra}_{\mathrm{I}}}{\mathrm{Ra}_{\mathrm{T}}} \sum_{j=1}^{4} \frac{\gamma_{j} \Phi_{j}}{0.76} \exp \left[-\frac{\Phi_{j}}{0.76}(1-Z)\right]
\end{aligned}
$$

Mass transfer equation

$$
\frac{\partial \varphi}{\partial \tau}+\operatorname{div}\left(\varphi \vec{V}-\frac{1}{\operatorname{Le}} \overrightarrow{\operatorname{grad}} \varphi\right)=0
$$

With the following initial and boundary conditions:

At initial time, the salty water is considered in rest condition and the pond has an ambient temperature.

$\tau=0: U=W=0, \theta=0$, and $P=0$

The initial dimensionless salt concentration is disturbed in the salinity gradient solar pond as follows:

- The LCZ is saturated in salt $(\varphi=1)$.

- In the NCZ, the concentration of salt increases with the depth as follows: $\varphi=\left(Z_{\mathrm{NCZ}}-Z\right) /\left(Z_{\mathrm{NCZ}}-Z_{\mathrm{LCZ}}\right)$.

- The UCZ is a zone without salt $(\varphi=0)$.

Concerning the boundary conditions, the vertical walls of the pond are thermally insulated and impermeable. At the bottom of the pond, we impose a zero mass flux and we assume that the heat flux is equal to the solar radiation reaching this depth. At the free surface of the pond, the corresponding boundary condition of velocities is: $\partial U / \partial Z=0$ and $W=0$.

We consider only half of the pond for reasons of symmetry. At the symmetrical vertical plane, the corresponding boundary conditions are: $U=0, \partial W / \partial X=0, \partial \theta / \partial X=0$, and $\partial \varphi / \partial X=0$. 
Heat losses through the top surface of the pond are detailed in Appendix.

\section{Numerical method}

The governing Equations (2 to 6) are discretized using the finite-volume method of Patankar (1980). In addition, the hybrid scheme interpolation is employed to discretize spatially the governing equations. The Alterning Directions Implicit (ADI) method is used to integrate temporally the discretized equations over a time step. The SIMPLER (Semi-Implicit Method for Pressure-Linked Equation Revised) algorithm (Patankar 1980) is employed to handle the coupling of pressure-velocity. A dimensionless time step $10^{-8}$ was found to be sufficient for producing accurate results at reasonable computed time.

In order to ensure the numerical results independency with respect to the number of nodes employed in the process of discretization, four uniform grid patterns spacing in $\mathrm{OX}$ and in $\mathrm{OZ}$ have been tested. The results obtained from this research, which were published in Boudhiaf and Baccar (2014), have shown that the uniform grid of $100 \times 100$ appears relatively suitable for the present work. In order to ensure the accuracy of numerical results, we validated the numerical code specifically developed for the present work in three ways. The results obtained from this study, which were published in Boudhiaf et al. (2012) and Boudhiaf and Baccar (2014) and hence are not repeated here for the sake of space, have shown a good comparison. The study of the grid independence, the validation of the numerical code specifically developed for the present research, and the algorithm of the numerical method have been detailed elsewhere (Boudhiaf et al. 2012; Boudhiaf and Baccar 2014; Boudhiaf 2013).

\section{Results and discussion}

In this work, we will present numerical results to study the importance of the effect of buoyancy ratio on the temporal evolution of temperature and concentration distributions in the three zones constituting the salinity gradient solar pond. The Prandtl and Schmidt numbers are kept constant $(\mathrm{Pr}=6$ and $\mathrm{Sc}=1000)$, which correspond to the average characteristics of salty water (Hammami et al. 2007; Boudhiaf et al. 2012; Boudhiaf and Baccar 2014). The results are generated for fixed values of thermal Rayleigh number, internal Rayleigh number, and aspect ratio $\left(\mathrm{Ra}_{\mathrm{T}}=10^{7}, \mathrm{Ra}_{\mathrm{I}}=1.4 \times 10^{8}\right.$, and $\left.A=3\right)$.

\section{Temporal evolution of temperature distribution}

Figures 2, 3, and 4 show the evolution of the dimensionless average temperature with time, respectively, in the UCZ, NCZ, and LCZ, during the absorption of solar radiation in the insulated salinity gradient solar pond for different values of buoyancy ratio $(N=1,2$, and 10) and for an aspect ratio $A=3$. It indicates clearly that the buoyancy ratio has an important effect on the temporal evolution of temperature distribution in the salinity gradient solar pond: the increase of the buoyancy ratio will decrease the temperature of salty water in the UCZ to a minimum value and will increase this temperature in the $\mathrm{LCZ}$ to a maximum value. In the $\mathrm{NCZ}$, the average temperature decreases when the buoyancy ratio increases from 1 to 10. At a fixed value of buoyancy ratio, we can observe an important increase of temperature with time, in the three zones constituting the salinity gradient solar pond due to the important solar radiation absorbed by salty water layers. In fact, in Figure 5, showing the temporal evolution of temperature distribution in the insulated salinity gradient solar pond for different values of buoyancy ratio, the temperature increases significantly in the LCZ and decreases in the NCZ and in the UCZ with the increase of the buoyancy ratio at a fixed time. This clearly demonstrates the role of the buoyancy ratio in the reduction of the heat transfer phenomenon in the upper and non-convective zone, which yields an elevation of temperature only in the storage zone. Also, in Figure 5, it is interesting to observe that for $N=1$, the solar pond

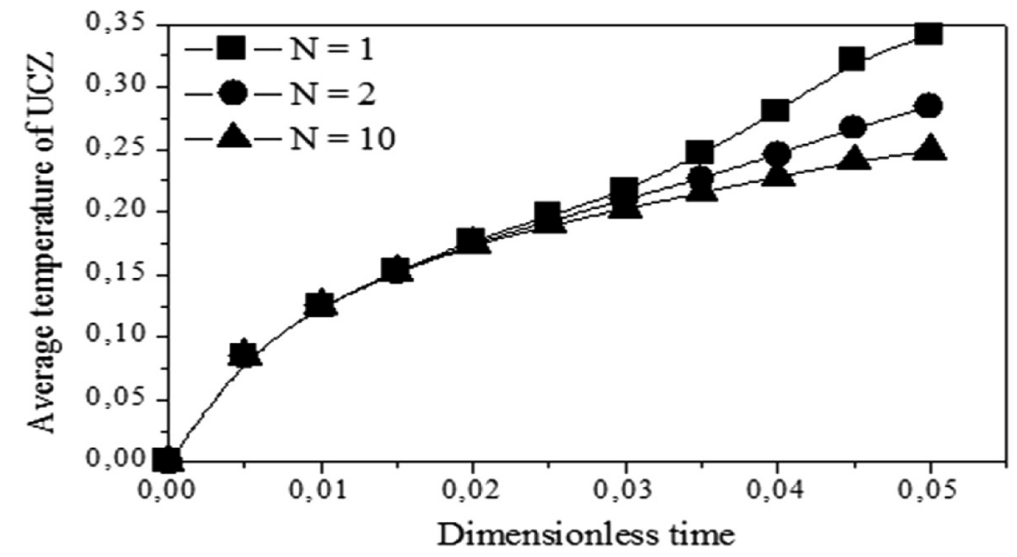

Figure 2 Temporal evolution of dimensionless average temperature of UCZ for different values of buoyancy ratio. $\left(\operatorname{Ra} a_{T}=10^{7}, \operatorname{Ra}_{1}=1.4 \times 10^{8}, A=3\right)$. 


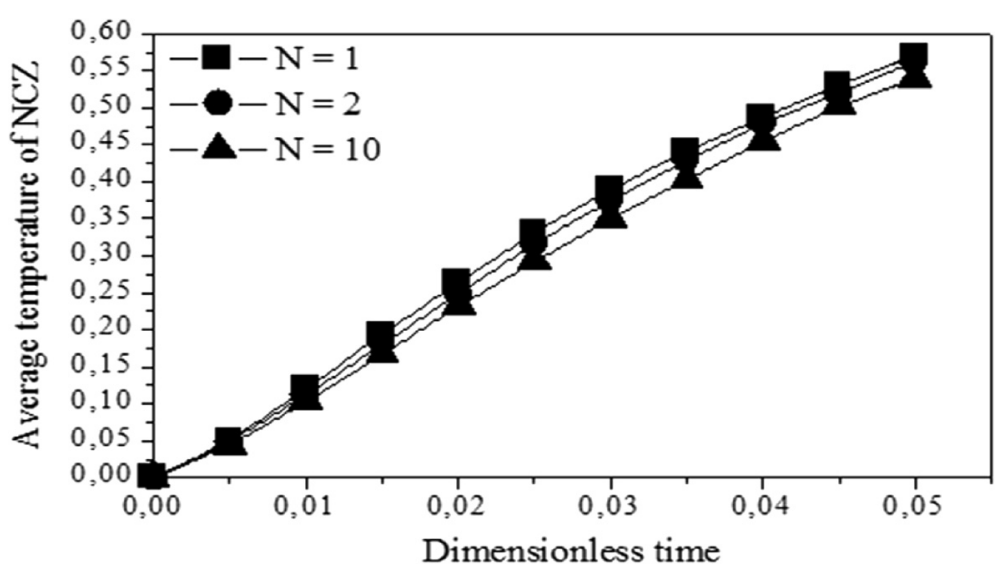

Figure 3 Temporal evolution of dimensionless average temperature of NCZ for different values of buoyancy ratio. $\left(\operatorname{Ra} \mathrm{T}_{\mathrm{T}}=10^{7}, \operatorname{Ra}_{1}=1.4 \times 10^{8}, A=3\right)$.

becomes a convective solar pond with the increase of dimensionless time of heating. For $N=2$, a thin nonconvective zone appears when the dimensionless time of heating increases. For $N=10$, diffusive heat transfer dominates convective heat transfer in the solar pond. For this value, the salinity gradient becomes very important to suppress the convection motions in the non-convective zone and to stabilize the solar pond.

\section{Temporal evolution of concentration distribution}

Figures 6, 7, and 8 show the transient evolution of the dimensionless average concentration of UCZ, NCZ, and LCZ, respectively, during the absorption of solar radiation in the salinity gradient solar pond for different values of buoyancy ratio $(N=1,2$, and 10) and for an aspect ratio $A=3$. For a fixed value of buoyancy ratio $N$, we can observe an increase of the concentration in both the UCZ and the NCZ and a decrease of the concentration in the LCZ with time. This is due to the diffusion of salt from the lower zone to the free surface of the pond. Furthermore, at a fixed value of the dimensionless time, it may be seen that the increase of the buoyancy ratio will decrease the average salt concentration of UCZ to a minimum value and will increase this average salt concentration in the LCZ to a maximum value. In the $\mathrm{NCZ}$, the average salt concentration decreases with the increase of the buoyancy ratio at a fixed value of the dimensionless time. In fact, in Figure 9, viewing the temporal evolution of concentration distribution in the insulated salinity gradient solar pond for different values of buoyancy ratio, salt concentration increases considerably in the LCZ to reach a maximum value and decreases in the UCZ and in the NCZ to attain a value near zero with the increase of the buoyancy ratio at a fixed time. This clearly demonstrates the role of the buoyancy ratio in the reduction of salt diffusion from the bottom to the free surface of the solar pond.

\section{Conclusions}

We have numerically studied the temperature and concentration distributions within a two-dimensional insulated salinity gradient solar pond under the effect of

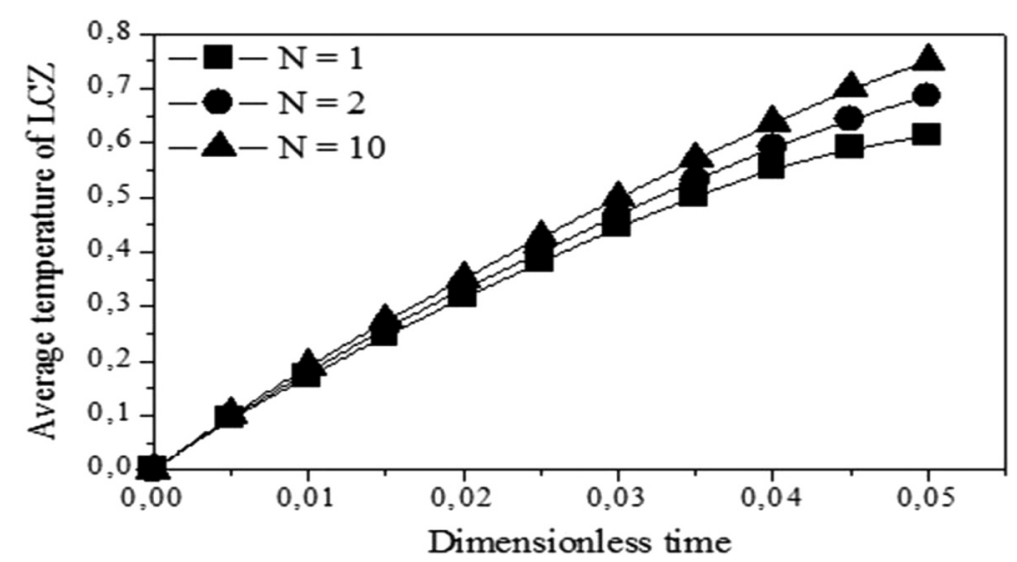

Figure 4 Temporal evolution of dimensionless average temperature of $L C Z$ for different values of buoyancy ratio. $\left(\mathrm{Ra}_{\mathrm{T}}=10^{7}, \mathrm{Ra}=1.4 \times 10^{8}, A=3\right)$. 

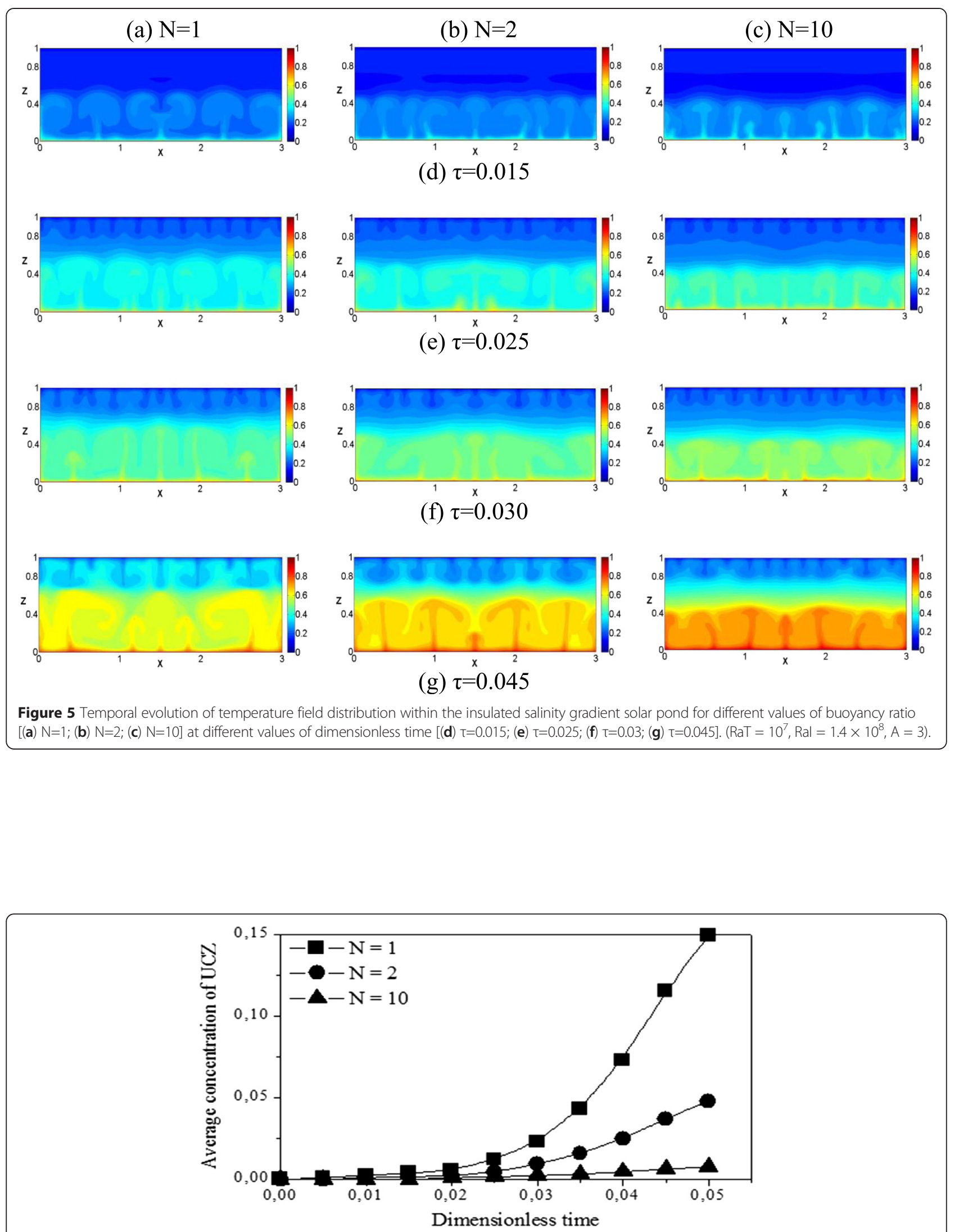

Figure 6 Temporal evolution of dimensionless average concentration of UCZ for different values of buoyancy ratio. $\left(\operatorname{Ra}_{\mathrm{T}}=10^{7}, \operatorname{Ra}_{1}=1.4 \times 10^{8}, A=3\right)$. 


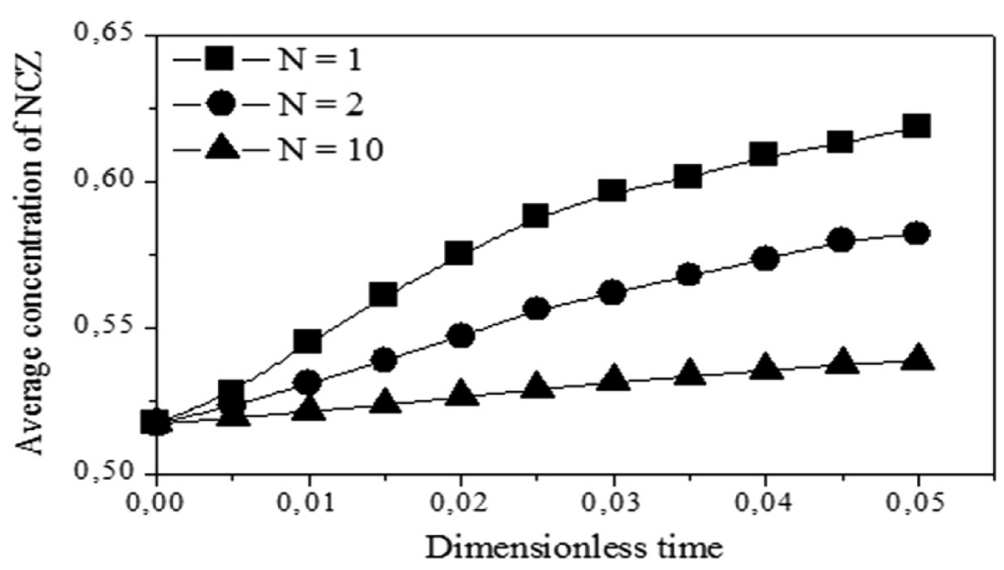

Figure 7 Temporal evolution of dimensionless average concentration of NCZ for different values of buoyancy ratio. $\left(\operatorname{Ra} \mathrm{T}^{=}=10^{7}, \operatorname{Ra} \mathrm{a}_{1}=1.4 \times 10^{8}, A=3\right)$.

the buoyancy ratio, in transient regime. The dimensionless equations obtained for the model have been solved numerically by employing the finite-volume method.

From the results obtained by this numerical study, we have concluded that the buoyancy ratio has a very important effect on the average temperature of UCZ, NCZ, and LCZ.

In addition, the buoyancy ratio has an important influence on the temporal evolution of average salt concentration in the UCZ, NCZ, and LCZ constituting the salinity gradient solar pond.

We have proved the existence of a salt diffusion from the lower convective zone to the upper convective zone. This diffusion of salt is generally due to the molecular diffusion.

We have also concluded that the buoyancy ratio is important to reduce the diffusion of salt from the bottom to the free surface of the pond and to increase the temperature in the lower convective zone.

\section{Nomenclature}

A Aspect ratio, $\left(A=L H^{-1}\right)$,

$C$ Concentration of solution, $\left(\mathrm{kg} \mathrm{m}^{-3}\right)$,

$\Delta C$ Difference of concentration, $\left(\Delta C=C_{\max }-C_{\text {min }}\right)$,

$C_{\mathrm{pa}}$ Specific heat of air, $\left(\mathrm{kJ} \mathrm{kg}^{-1{ }^{\circ}} \mathrm{C}^{-1}\right)$,

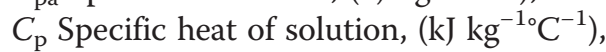

$D$ Diffusion coefficient, $\left(\mathrm{m}^{2} \mathrm{~s}^{-1}\right)$,

$H$ Height, (m),

$h_{\mathrm{c}}$ Convective heat transfer coefficient, $\left(W^{-2{ }^{\circ}} \mathrm{C}^{-1}\right)$,

$L$ Length, (m),

LCZ Lower convective zone,

$L_{\mathrm{v}}$ Latent heat of water evaporation, $\left(\mathrm{J} \mathrm{kg}^{-1}\right)$,

Le Lewis number,

$N$ buoyancy ratio,

NCZ Non-convective zone,

$p$ Pressure, $(\mathrm{Pa})$,

$P$ Dimensionless pressure,

Pr Prandtl number,

$P_{\mathrm{s}}$ Vapor pressure of water at the pond's surface, $(\mathrm{Pa})$, $P_{\mathrm{v}}$ Partial pressure of water vapor in the air, $(\mathrm{Pa})$,

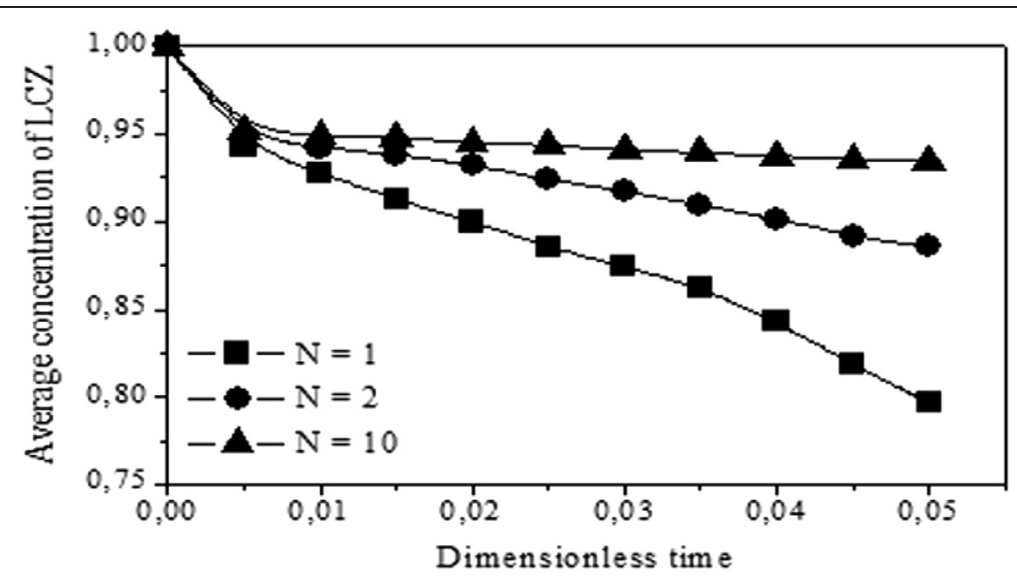

Figure 8 Temporal evolution of dimensionless average concentration of $L C Z$ for different values of buoyancy ratio. $\left(\operatorname{Ra} a_{T}=10^{7}, \operatorname{Ra}_{1}=1.4 \times 10^{8}, A=3\right)$. 


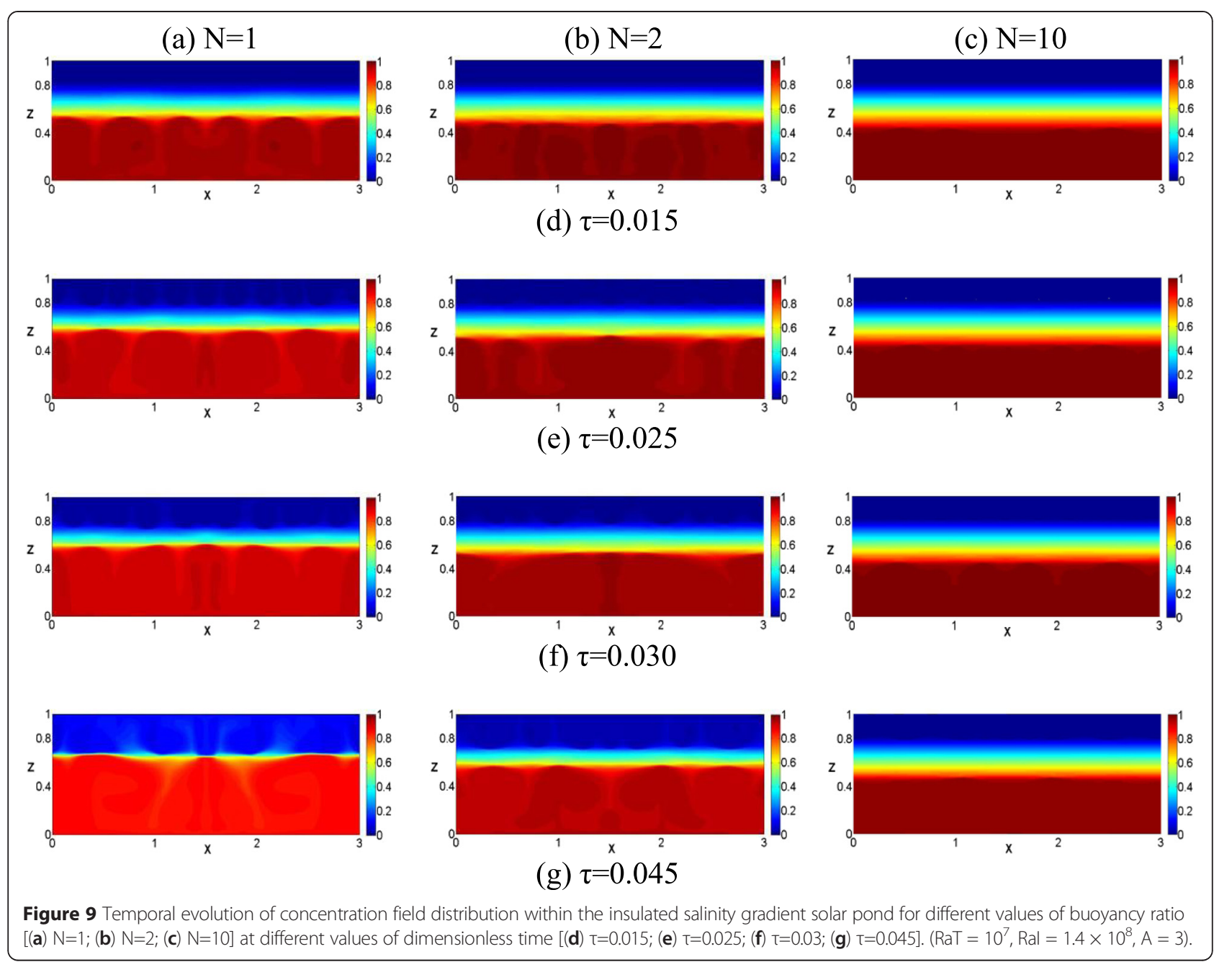

$P_{\text {atm }}$ Atmospheric pressure, $(\mathrm{Pa})$,

$Q_{\mathrm{c}}$ Heat losses due to convection, ( $\mathrm{W} \mathrm{m}^{-2}$ ),

$Q_{\mathrm{e}}$ Heat losses due to evaporation, $\left(\mathrm{W} \mathrm{m}^{-2}\right)$,

$Q_{\mathrm{r}}$ Heat losses due to radiation, ( $\mathrm{W} \mathrm{\textrm {m } ^ { - 2 }}$ ),

$q_{0}$ Solar radiation penetrating the top surface of the pond, $\left(\mathrm{W} \mathrm{m}^{-2}\right)$,

$q(z)$ Solar radiation absorbed at depth $z,\left(\mathrm{~W} \mathrm{~m}^{-2}\right)$,

$\mathrm{Ra}_{\mathrm{T}}$ Thermal Rayleigh number,

$\mathrm{Ra}_{\mathrm{I}}$ Internal Rayleigh number,

$R_{\mathrm{h}}$ Relative humidity,

$\mathrm{Ra}_{\mathrm{S}}$ Solutal Rayleigh number,

Sc Schmidt number,

$t$ Time, (s),

$\Delta T$ Difference of temperature, $\left(\Delta T=T_{\max }-T_{\min }\right)$,

$T$ Temperature, $\left({ }^{\circ} \mathrm{C}\right)$,

$T_{\text {max }}$ Maximum temperature, $\left({ }^{\circ} \mathrm{C}\right)$,

$T_{\text {min }}$ Minimum temperature, $\left({ }^{\circ} \mathrm{C}\right)$,

$T_{\mathrm{s}}$ Temperature at the top surface of the pond, $\left({ }^{\circ} \mathrm{C}\right)$,

$T_{\mathrm{a}}$ Ambient temperature, $\left({ }^{\circ} \mathrm{C}\right)$,

$T_{\text {sky }}$ Sky temperature, $\left({ }^{\circ} \mathrm{C}\right)$,

$V$ Wind average velocity, $\left(\mathrm{m} \mathrm{s}^{-1}\right)$, $u, w$ Velocity components, $\left(\mathrm{m} \mathrm{s}^{-1}\right)$,

$U, W$ Dimensionless velocity components,

UCZ Upper convective zone,

$x, z$ Cartesian coordinates, $(\mathrm{m})$,

$X, Z$ Dimensionless Cartesian coordinates,

$Z_{\mathrm{LCZ}}$ Dimensionless depth of the solar pond measured at the LCZ-NCZ boundary,

$Z_{\mathrm{NCZ}}$ Dimensionless depth of the solar pond measured at the NCZ-UCZ boundary,

Greek symbols

$\alpha$ Thermal diffusivity, $\left(\mathrm{m}^{2} \mathrm{~s}^{-1}\right)$,

$\beta_{\mathrm{T}}$ Thermal expansion coefficient, $\left(\mathrm{K}^{-1}\right)$,

$\beta_{\mathrm{C}}$ Concentration expansion coefficient, $\left(\mathrm{m}^{3} \mathrm{~kg}^{-1}\right)$,

$\lambda_{\mathrm{w}}$ Thermal conductivity of water, (W $\mathrm{m}^{-1} \mathrm{~K}^{-1}$ ),

$v$ Cinematic viscosity, $\left(\mathrm{m}^{2} \mathrm{~s}^{-1}\right)$,

$\mu$ Dynamic viscosity, $\left(\mathrm{kg} \mathrm{m}^{-1} \mathrm{~s}^{-1}\right)$,

$\rho$ Density, $\left(\mathrm{kg} \mathrm{m}^{-3}\right)$,

$\varphi$ Dimensionless concentration,

$\theta$ Dimensionless temperature,

$\tau$ Dimensionless time,

$\varepsilon$ Salty water extinction coefficient, $\left(\mathrm{m}^{-1}\right)$, 
$\varepsilon_{\mathrm{w}}$ Water emissivity, $\sigma$ Constant of Stefan-Boltzmann, (W m ${ }^{-2} \mathrm{~K}^{-4}$ ), $\Phi$ Dimensionless absorption coefficient, $(\Phi=\varepsilon H)$, Subscripts

a Ambient,

b Bottom,

w Water,

1 Local,

max Maximum value,

min Minimum value.

\section{Appendix}

The model salinity gradient solar pond is supposed to be well insulated: heat losses from the top surface of the pond occur due to convection, evaporation, and radiation.

The heat losses by convection are given by Kurt et al. (2000); Mansour et al. (2004); and Kurt et al. (2006):

$$
Q_{\mathrm{c}}=h_{\mathrm{c}}\left(T_{\mathrm{s}}-T_{\mathrm{a}}\right)
$$

where $h_{\mathrm{c}}$ is the wind convective heat transfer coefficient, which depends on the velocity of wind, and is given by Kurt et al. (2000); Mansour et al. (2004); and Kurt et al. (2006):

$$
h_{\mathrm{c}}=5.7+3.8 \mathrm{~V}
$$

The heat losses by evaporation are given by Kurt et al. (2000); Mansour et al. (2004); and Kurt et al. (2006):

$$
Q_{\mathrm{e}}=\frac{L_{\mathrm{v}} h_{\mathrm{c}}\left(P_{\mathrm{s}}-P_{\mathrm{v}}\right)}{1.6 C_{\mathrm{pa}} P_{\mathrm{atm}}}
$$

where $P_{\mathrm{s}}$ is the vapor pressure of water evaluated at the surface temperature

$$
P_{\mathrm{s}}=\exp \left(18.403-\frac{3885}{T_{\mathrm{s}}+230}\right)
$$

and $P_{\mathrm{v}}$ is the partial pressure of water vapor in the ambient air evaluated at the ambient temperature

$$
P_{\mathrm{v}}=R_{\mathrm{h}} \exp \left(18.403-\frac{3885}{T_{\mathrm{a}}+230}\right)
$$

The heat losses due to radiation from the top surface to the sky are given by Kurt et al. (2000); Mansour et al. (2004); and Kurt et al. (2006):

$$
Q_{\mathrm{r}}=\varepsilon_{\mathrm{w}} \sigma\left(\left(T_{\mathrm{s}}+273.15\right)^{4}-\left(T_{\text {sky }}+273.15\right)^{4}\right)
$$

where $T_{\text {sky }}$ is the sky temperature given as follows (Joshi and Kishore 1984; Parmelee and Anbele 1952):

$$
T_{\text {sky }}=T_{\mathrm{a}}\left[0.55+0.61 \sqrt{P_{\mathrm{v}}}\right]^{0.25}
$$

\section{Competing interests}

The author declares that he has no competing interests.
Authors' contributions

It is an individual work. The author read and approved the final manuscript.

\section{Authors' information}

RB was born in Kasserine, Tunisia. He has the Ph.D. degree in ChemicalProcess Engineering at the National School of Engineers of Gabès (ENIG), University of Gabès, Tunisia. He is a member in the Laboratory of ElectroMechanical Systems at the National School of Engineers of Sfax (ENIS), University of Sfax, Tunisia. He is also an assistant professor of chemicalprocess engineering in the Higher Institute of Biotechnology of Sfax (ISBS), University of Sfax, Tunisia.

Research interests: renewable energy; energy storage; energy conversion; double diffusive natural convection; solar collectors; solar distillers; salinity gradient solar ponds; numerical simulation.

$\mathrm{MB}$ is the director of the Computational Fluid Dynamics and Transfer Phenomena (CFDTP), and he is a professor in the Mechanical Engineering Department of the National School of Engineers of Sfax (ENIS), University of Sfax, Tunisia.

\section{Acknowledgements}

The author wishes to acknowledge Professor Mounir Baccar, the director of Computational Fluid Dynamics and Transfer Phenomena (National School of Engineers of Sfax, University of Sfax, Tunisia), for helpful suggestions and fruitful discussions.

Received: 14 July 2014 Accepted: 23 April 2015

Published online: 28 July 2015

\section{References}

Angeli, C, \& Leonardi, E. (2004). A one-dimensional study of the salt diffusion in a salinity gradient solar pond. International Journal of Heat and Mass Transfer, $47,1-10$.

Boudhiaf R. Etude numérique de la convection naturelle thermosolutale dans un étang de stockage d'énergie solaire [in French]. PhD thesis, National School of Engineers of Gabès, University of Gabès, Gabès, Tunisia; 2013.

Boudhiaf, R, \& Baccar, M. (2014). Transient hydrodynamic, heat and mass transfer in a salinity gradient solar pond: a numerical study. Energy Conversion and Management, 79, 568-580

Boudhiaf, R, Moussa, AB, \& Baccar, M. (2012). A two-dimensional numerical study of hydrodynamic. Heat and Mass Transfer and Stability in a Salt Gradient Solar Pond, Energies, 5, 3986-4007.

El-Sebaii, AA, Ramadan, MRI, Aboul-Enein, S, \& Khallaf, AM. (2011). History of the solar ponds: a review study. Renew Sust Energy Rev, 15, 3319-3325.

Hammami, M, Mseddi, M, \& Baccar, M. (2007). Transient natural convection in an enclosure with vertical solutal gradients. Solar Energy, 81, 476-487.

Joshi, A, \& Kishore, VA. (1984). A practical collector efficiency equation for non-convecting solar ponds. Solar Energy, 33(5), 391-395.

Karakilcik, M, Kıyma, K, \& Dincer, I. (2006). Experimental and theoretical temperature distributions in a solar pond. International Journal of Heat and Mass Transfer, 49, 825-835.

Kurt, H, Halici, F, \& Binark, AK. (2000). Solar pond conception-experimental and theoretical studies. Energy Conversion and Management, 41, 939-951.

Kurt, H, Halici, F, \& Binark, AK. (2006). Experimental and numerical analysis of sodium-carbonate salt gradient solar-pond performance under simulated solar-radiation. Applied Energy, 83, 324-342.

Mansour, RB, Nguyen, CT, \& Galanis, N. (2004). Numerical study of transient heat and mass transfer and stability in a salt-gradient solar pond. International Journal of Thermal Sciences, 43, 779-790.

Ould Dah, MM, Ouni, M, Guizani, A, \& Belghith, A. (2005). Study of temperature and salinity profiles development of solar pond in laboratory. Desalination, 183, 179-185

Ould Dah, MM, Ouni, M, Guizani, A, \& Belghith, A. (2010). The influence of the heat extraction mode on the performance and stability of a mini solar pond. Applied Energy, 87, 3005-3010.

Ouni, M, Guizani, A, \& Belghith, A. (1998). Simulation of the transient behaviour of a salt gradient solar pond in Tunisia. Renewable Energy, 14, 69-76.

Parmelee GV, Anbele WW (1952). Radiant energy emissions of atmosphere and ground. ASHVE Trans, 58-85.

Patankar, SV. (1980). Numerical heat transfer and fluid flow. Washington: Hemisphere Publishing Corporation.

Rabl, A, \& Nielsen, CE. (1975). Solar ponds for space heating. Solar Energy, 17, 1-12. 
Sakhrieh, A, \& Al-Salaymeh, A. (2013). Experimental and numerical investigations of salt gradient solar pond under Jordanian climate conditions. Energy Conversion and Management, 65, 725-728.

Sezai, I, \& Tasdemiroglu, E. (1995). Effect of bottom reflectivity on ground heat losses for solar ponds. Solar Energy, 55(4), 311-319.

Singh, TP, Singh, AK, \& Kaushik, ND. (1994). Investigations of thermodynamic instabilities and ground storage in a solar pond by simulation model. Heat Recovery Systems, 14(2), 401-407.

Sodah, MS, Kaushik, ND, \& Rao, SK. (1981). Thermal analysis of three zone solar pond. International Journal of Energy Research, 5, 321-340.

Suarez, F, Tyler, SW, \& Childress, AE. (2010). A fully coupled, transient doublediffusive convective model for salt-gradient solar ponds. International Journal of Heat and Mass Transfer, 53, 1718-1730.

Submit your manuscript to a SpringerOpen ${ }^{\odot}$ journal and benefit from:

- Convenient online submission

- Rigorous peer review

- Immediate publication on acceptance

- Open access: articles freely available online

- High visibility within the field

- Retaining the copyright to your article

Submit your next manuscript at $>$ springeropen.com 